NBSIR 75.663 $(R)$

Color Requirements for the Marking of Obstructions

Robert L. Booker

Illuminating Engineering Group

Optical Radiation Section

Heat Division

Institute for Basic Standards

National Bureau of Standards

March 1975

Final Report

Prepared for

Federal Aviation Administration

Systems Research and Development Service

Washington, D. C. 20553 

NBSIR 75-663

\section{COLOR REQUIREMENTS FOR THE MARKING OF OBSTRUCTIONS}

Robert L. Booker

Illuminating Engineering Group *

Optical Radiation Section

Heat Division

Institute for Basic Standards

National Bureau of Standards

March 1975

Final Report

* The work described herein was accomplished while the author was in the Sensory Environment Section, Center for Building Technology, Institute for Applied Technology.

Prepared for

Federal Aviation Administration

Systems Research and Development Service

Washington, D. C. 20553

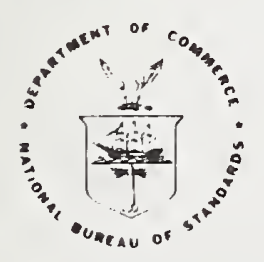

U. S. DEPARTMENT OF COMMERCE, Frederick 8. Dent, Secretary

NATIONAL BUREAU OF STANDARDS, Richard W. Roberts. Director 


\section{CONTENTS}

\section{Page}

Abstract $\ldots \ldots \ldots \ldots \ldots \ldots \ldots \ldots \ldots \ldots \ldots \ldots$ iv

1. Introduction $\ldots \ldots \ldots \ldots \ldots \ldots \ldots \ldots \ldots \ldots \ldots \ldots \ldots \ldots$

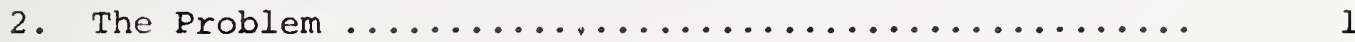

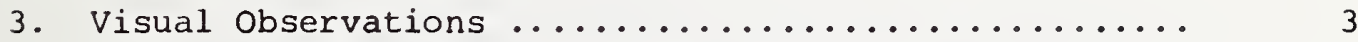

3.1 Ground Observations in Washington Area ........ 3

3.2 Air Observations in Washington Area .......................... 4

3.3 Air Observations in Surrounding Area .......... 4

4. Analysis of Flight Observations ........................ 4

5. Colorimetry of Paint Chips .................. 10

6. Discussion of Previous Experiments ............. 11

7. Recommendations and Discussion ................ 14

8. Field Implementation ...................... 16

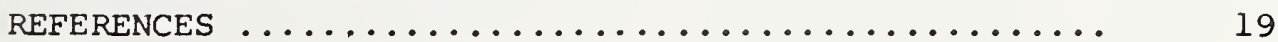

APPENDIX A - Group on First Field Trip ........... 20 


\section{LIST OF FIGURES}

Figure No.

Page

1. Portion of Chromaticity Diagram Showing Coordinate Locations of Paint Chips from Towers and Various Chromaticity Boundaries for Surface

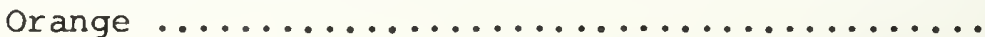

2. Eight Coordinate Positions of Color Chips Proposed for Inspection of In-Service Orange

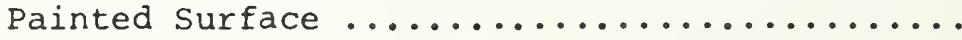




\section{LIST OF TABLES}

\section{Table}

No.

1. Chromaticity Coordinates and Luminance Factor (Reflectance) of Paint Chips from Towers in Washington Metropolitan Area...

2. Comments Resulting from Helicopter Flight Viewing Towers in Washington Metropolitan Area on June 4, 1974............

3. Chromaticity Coordinates, Luminance Factors (Reflectance) of Paint Chips, and Comments Relating to Towers Observed During

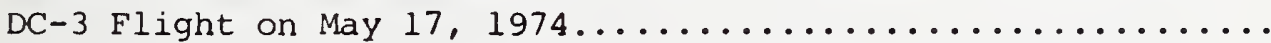

4. Description of Six Colors Used by Middleton..............

5. Chromaticity Coordinates (Source C) of Color Chips Proposed for Inspection of In-Service orange Painted Surfaces........ 


\begin{abstract}
Present methods and problems associated with the surface marking of obstructions to aviation, such as tall towers, are discussed. The correlation of subjective evaluations of appearance, from both ground and air observations, with the physical characteristics of the orange-painted sections of selected towers is described. Recommendations regarding the in-service appearance of orange paint consist of expanded chromaticity limits in combination with specific restrictions on reflectance. A suggested method of field implementation consists of using color tolerance charts displaying colored squares which depict the limit of the chromaticity and reflectance requirements.
\end{abstract}




\section{INTRODUCTION}

The Federal Aviation Administration requires that all obstructions, which pose a potential hazard to aircraft, be marked in a specific manner. Included in this category are towers rising 200 feet or more above the established terrain. They must be painted in alternating bands of white and orange in accordance with the provisions of Advisory Circular 70/7460-1. The purpose of this requirement is to increase the conspicuity of the towers when viewed from the air during daylight hours. Under certain viewing conditions, a tower's painted pattern is recognizable before its outline.

It should be pointed out that the color aviation orange is used for its proven characteristic of conspicuity under a wide range of environmental conditions. It is unimportant that an aviator identify its orange color as such. It is only important that he notice the presence of an object painted with it. It is also for reasons of increased conspicuity that the luminance factors (reflectances) of the white and orange paints used in painting the towers are markedly different. Aviation surface orange has a reflectance of approximately 148 while aviation white is about $88 \%$ when the paints are fresh.

In order to control the orange color of towers, the FAA published an "Aviation Surface Orange Color Tolerance Chart" in May, 1971. The chart displays a grouping of seven orange colored squares including a target color in the center and six surrounding tolerance limit colors which differ from the target color in varying degrees of hue, lightness, or saturation. The chart has two vertical openings which allow an orange surface to be visually evaluated when the chart is placed upon it.

Information on the reverse sides of the color tolerance chart lists both the CIE data (Source C) and the Munsell notation for each of the seven orange squares. A brief explanation of the Munsell System is given as well as an explanation of the usage of the chart. Two available paints which meet the requirements of the specification are also listed.

2. THE PROBLEM

The Color Tolerance Chart is an effective means of controlling the color of newly painted towers. However, the color of a newly painted exterior surface soon begins to deteriorate due to action 
of the weather and elements. The orange painted sections of the towers change and soon reach a point where they are outside the limits of the color tolerance chart. FAA Advisory Circular AC 70/7460-1 is not specific in that it recommends that ". . . surfaces should be repainted whenever the color changes noticeably or its effectiveness is impaired by scaling or chipping." A recommendation of the International Civil Aviation Organization (ICAO) is similar in tone -- "The specifications of surface colors apply only to freshly colored surfaces. Colors used for surface markings usually change with time. Due diligence should be exercised to ensure that surfaces are renewed whenever they have changed color noticeably." The problem is compounded because a paint's useful life usually extends beyond its chromatic life. In other words, the paint will continue to protect the tower's surface even after the paint has lost most of its chromatic qualities.

Consequently, the FAA is considering the use of additional color tolerance charts, to display acceptable limits of fading, for use in determining when a tower should be repainted.

\section{VISUAL OBSERVATIONS}

Three separate field trips were conducted in order to evaluate the appearance of various towers.

\subsection{Ground Observations in Washington Area.}

The first field trip, which consisted of ground observations, occurred on November 19, 1973, when a group comprised of 10 individuals from the Federal Aviation Administration, Federal Communications Commission, and the National Bureau of Standards (See Appendix A) visited seven tower sites in the Washington, D. C. area.

As the towers were visited, each of the participants from the FAA and FCC was questioned by the senior NBS participant regarding his opinion of the appearance (color) of the painted orange surfaces. A seven-point scale was used in ranking the towers with seven corresponding to the most satisfactory rating and one to the least satisfactory rating. These subjective evaluations were recorded and later used in correlating the visual assessments with the physical data obtained from the paint chips which were gathered at most of the sites. These results are presented in Table 1 and are discussed more fully in section 5 of the report. An interim report was issued regarding these findings [1]. 
TABLE 1

Chromaticity Coordinates and Luminance Factor (Reflectance) of Paint

Chips from Towers in Washington Metropolitan Area

Average of the

\begin{tabular}{|c|c|c|c|c|c|c|}
\hline & Tower & $x$ & $y$ & $\mathrm{Y} 8$ & Observers' & Ratings \\
\hline \multirow[t]{2}{*}{ A } & - WDCA & 0.521 & 0.360 & 22.2 & 6.1 & \\
\hline & & .528 & .364 & 21.3 & & \\
\hline & - WMAL & .510 & .356 & 16.1 & 6.0 & \\
\hline & & .504 & .355 & 15.3 & & \\
\hline & & .470 & .351 & 15.1 & & \\
\hline \multirow[t]{3}{*}{ C } & - AT\&T & .477 & .351 & 21.2 & 4.5 & \\
\hline & & .479 & .352 & 21.2 & & \\
\hline & & .461 & .347 & 16.4 & & \\
\hline \multirow{3}{*}{\multicolumn{2}{|c|}{$D$ - WRC }} & .539 & .369 & 9.9 & 3.2 & \\
\hline & & .477 & .367 & 11.7 & & \\
\hline & & .492 & .364 & 10.4 & & \\
\hline \multirow{2}{*}{\multicolumn{2}{|c|}{$E-P E P C O$}} & .459 & .345 & 14.4 & 3.1 & \\
\hline & & .441 & .348 & 21.9 & & \\
\hline \multirow{2}{*}{\multicolumn{2}{|c|}{$F-$ WTOP-2 }} & .601 & .349 & 19.77 & 6.4 & \\
\hline & & .578 & .354 & 19.77 & & \\
\hline
\end{tabular}




\subsection{Air Observations in Washington Area}

These same towers were later observed from the air during a helicopter flight the afternoon of June 4, 1974. Some additional structures along the flight path were also observed. The comments of the three NBS observers are presented in Table 2.

\subsection{Air Observations in Surrounding Area.}

A different group of towers, consisting of 12 locations over a 4-state area, was observed from a DC-3 aircraft, operated by the FAA, on May 17, 1974. After locating a particular tower, the pilot usually circled at close range. Occasionally the pilot was asked to circle at longer distances, ranging up to 4 miles. The observations presented in Table 3 represent those of the NBS participants.

\section{ANALYSES OF FLIGHT OBSERVATIONS}

Circling the towers during the DC-3 flight served to illustrate the degree to which a tower's conspicuity can vary as a function of viewing angle and viewing conditions. For example, in the up-sun direction, the towers are silhouetted against a brighter sky background and, as such, have a negative contrast -- see Middleton [2]. Under these conditions, their contrast with the sky is almost independent of the color or the condition of the paint. Viewing upsun is a condition where the tower is viewed against a bright, illuminated sky, with the sun far enough from the line of sight so that it is not a glare source.

Down-sun is used to describe viewing conditions where the sun is behind the observer as he views the tower. Under these conditions, the white of the tower usually appears to be much more luminous than its background and hence is highly conspicuous and the orange is conspicuous as a chromatic signal. However, if under down-sun viewing conditions, the background of the tower is a sun-lighted cloud, the contrast between the white of the tower and the background will be very low, and the white will often not be visible.

The foregoing discussion of up-sun and down-sun tower visibility assumes a sky background. The situation is obviously different for a terrestrial background, which is much darker.

Viewing up-sun against a shaded terrestrial background such as hills or trees, the tower appears dark against its background, since the sun is behind the tower. Under these conditions, colors are difficult to distinguish and the chromatic aspects of orange 
TABLE 2

Comments Resulting from Helicopter Flight

Viewing Towers in Washington Metropolitan Area

on June 4,1974

Area/Tower

Comments/Appearance

Andrews AFB

- glide path shelter and other small buildings very good

- transmissometer stand - unacceptable

- water tower - good to very good, depending on angle of view

Anacostia

various smokestacks - all had faded paint -

appearance with down-sun viewing acceptable

N. W. Washington

(WRC, WTOP, WTTG) highly visible in silhouette as seen from Georgetown - white almost invisible from Chain Bridge area (about $90^{\circ}$ to sun)

PEPCO terrestrial background-being repainted - much improved

WMAL 4 guyed towers - good appearance - terrestrial background - white better than orange

WMAL (old)

self-standing - appearance at limit of acceptability

WRC/AM

4 slender guyed towers - not so good - towers present small surface area - paint may be OK background includes brick buildings

WJMD

short tower in golf course - terrestrial background - very good from all angles of view

WDCA

candelabra-River Road - poor - lacks chromatic appearance from all angles of view

WTTG \& WTOP good - shorter WTOP tower has been repainted wave guides not painted

WRC/TV poor - orange appears very dark

American University

somewhat better than WRC/TV - near limit of acceptability

Virginia

group of 3 towers - microwave tower acceptable others poor - tallest, self-standing, has desaturated, yellowish orange - nearby water tower excellent

Note - See Table 1 for chromaticity coordinates of orange paint on Washington area towers 


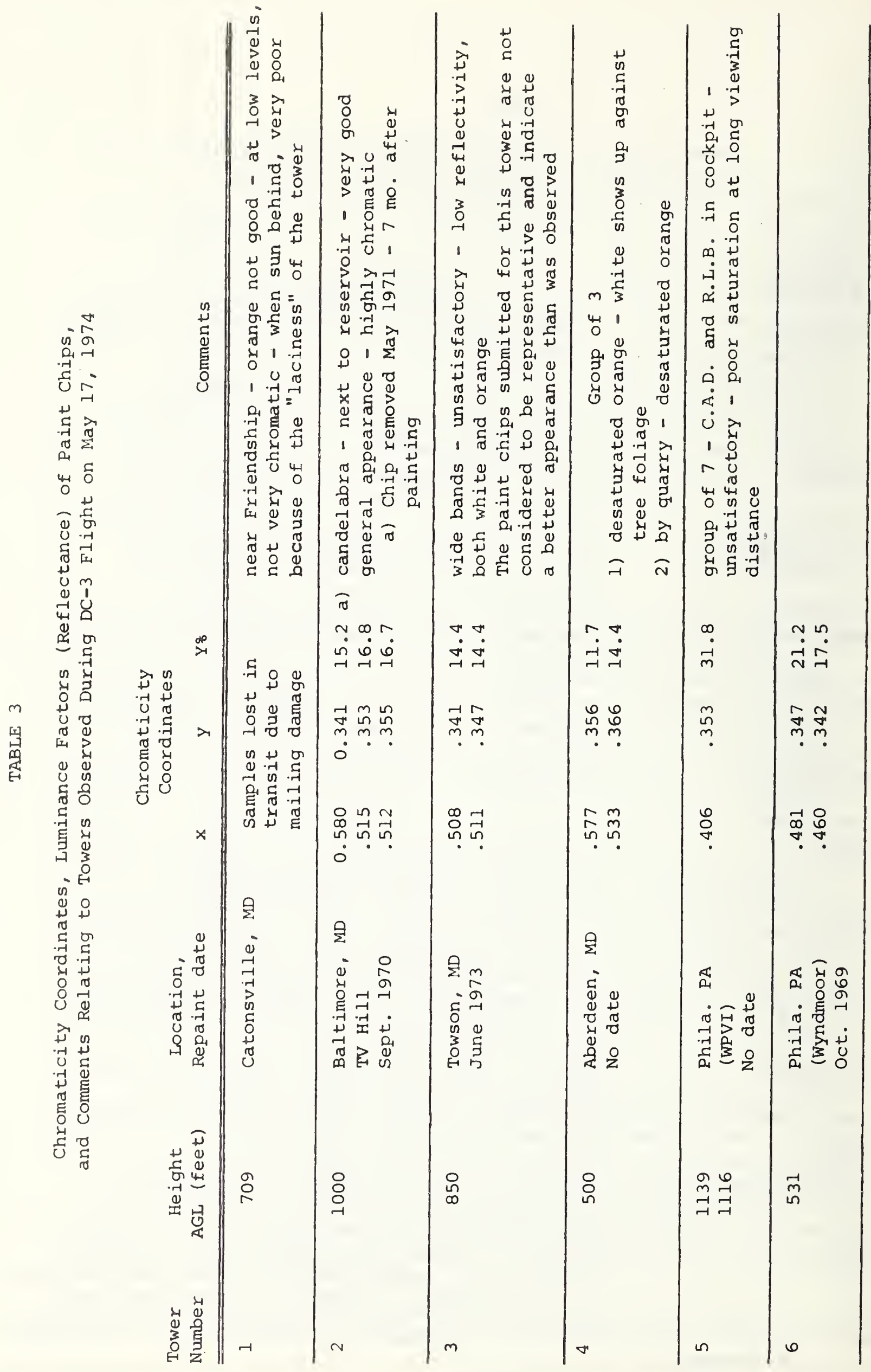




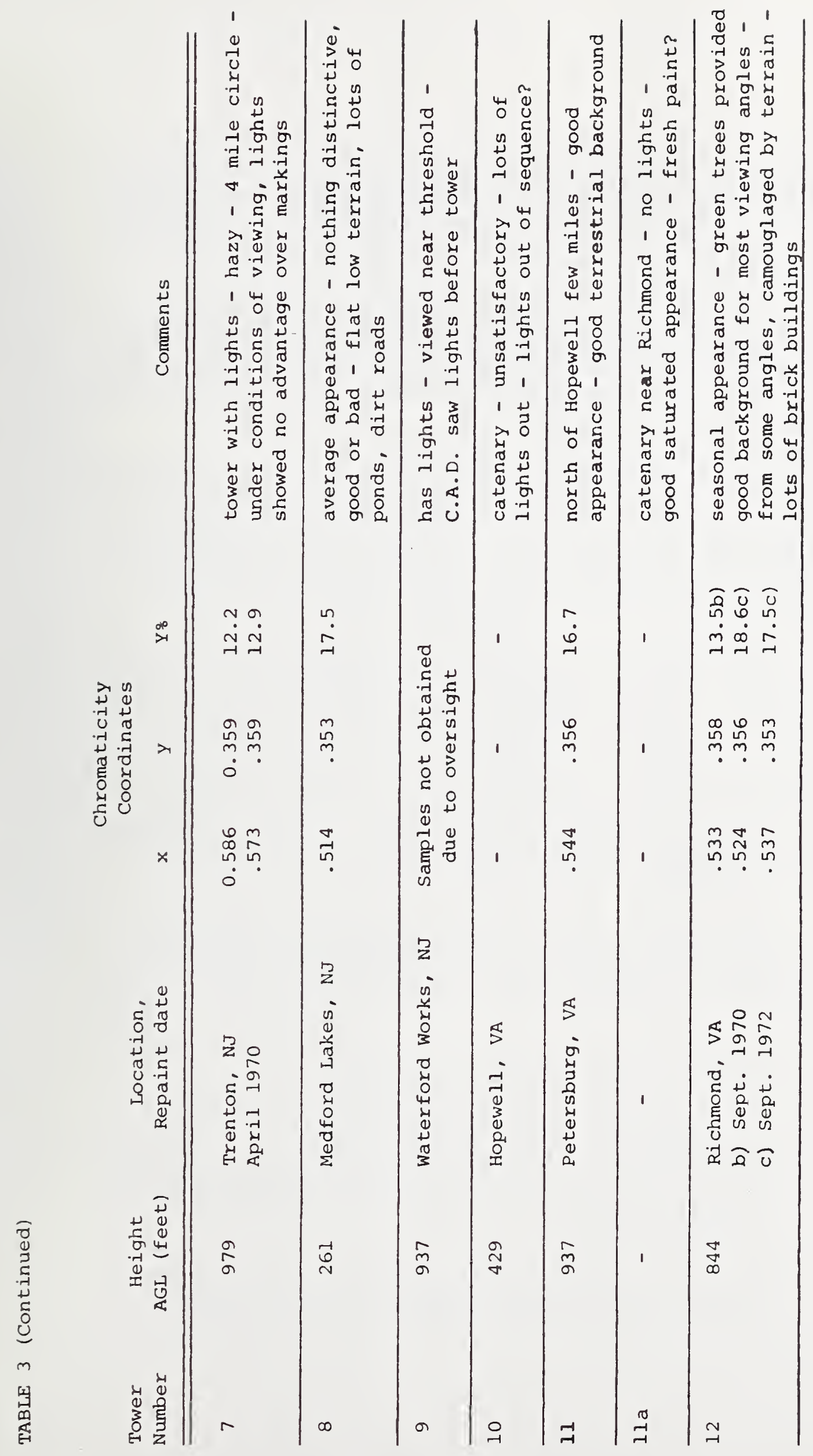


surfaces are not apparent. The white portion in a tower's painted pattern becomes its distinguishing factor, since it is the only part that stands out against the dark background. The necessity for a white paint of high reflectance under these circumstances is obvious.

Viewing down-sun against a terrestrial background does not present any special problems. The combination of terrestrial background and direct illumination on the viewed surface of the tower tends to make the tower very conspicuous, with good coloring, even if the paint is faded.

Up-sun and down-sun viewing are, of course, only two of the many possible viewing angles. When consideration is given to the variations that occur in backgrounds, a truly large number of viewing situations is possible. Because of this high number of combinations of viewing conditions which must be accommodated, maintenance of a pattern having a high reflectance in white and high chromaticness in orange is essential.

Tower number 12, in Richmond, is a good case for the use of lights. From some angles of view, its appearance will have a seasonal variation, depending on the extent of foliage on the terrestrial background. Since our observations took place in mid-May, the trees were leafed-out and provided a good visual background. However, from some angles of view, the background was a mixture of concrete pavement and red brick buildings, which effectively camouflaged the tower. This latter condition is more predominant in the winter months, when the trees are without leaves.

Towers number 11 and lla showed the distinct advantage of (apparently) new paint. Their appearance was greatly enhanced, on a comparative basis, by the saturated colors of the orange paint.

Generally speaking, there are 3 separate ways in which a tower's appearance is likely to deteriorate:

a) the orange paint can fade (desaturate) and become lighter.

b) the orange paint can get darker and desaturate towards neutral.

c) both the orange and white paint can get darker while maintaining the same chromaticity (hue and chroma). 
The first and second conditions characterize the towers viewed from the ground during the earlier field trip, based on the colors of the paint chips [1].

As previously mentioned, comments relating to the helicopter flight are presented in Table 2. Towers supported by guy wires are identified as such in the comments. Guyed towers are more slender and, depending on the viewing distance, are frequently less conspicuous than self-standing towers of the same height, which present a larger painted surface to an observer.

Circumstances require special examination of the data and comments regarding the WDCA tower. The data in Table 1 show a high rating from the ground observers and fairly high saturation for an in-service orange paint. In view of this, the comments resulting from the helicopter flight, Table 2, that the appearance of the WDCA tower was "poor" and "lacks chromatic appearance from all angles of view" would seem to be contradictory. However, the ground observations had revealed that the interior exposed surfaces of the WDCA tower had not been painted and had a deteriorated appearance. The ground observers based their evaluation (rating) of the tower's appearance upon those surfaces that were painted. The consequences of this were borne out in the ultimate test, appearance from the air. This example should be ample proof for the necessity of painting all exposed surfaces of skeletal structures.

The new (100-foot) stripes are much better than the older 40-foot wide stripes in making a tower conspicuous. Consideration should be given to synchronizing the painted patterns of towers in close proximity to one another despite differences in height. For instance, if two or more towers of differing heights are located within an area of one-half mile or less in diameter, then the band width for all towers would be based on the height of the tallest tower, as specified in AC 70/7460. However, the width of the uppermost orange band of the shorter tower should be adjusted, as appropriate, to insure that the top of the tower is painted orange.

When the band widths of such towers are not arranged to coincide with one another, under some angles of view the towers can line up in such a manner that, while not obscuring one another, the combined patterns present a mottled mixture of orange and white that makes the towers less conspicuous. 
Orange paint chips were gathered at six of the tower sites during the observations in the Washington metropolitan area to be used in correlating the subjective evaluations of the towers' appearance with a physical description of the orange paint. The paint chips were gathered from the base of the towers.

Subsequent to the DC-3 flight, appropriate tower operators were contacted requesting that orange paint chips from the base of the tower be sent to us. Information was also requested regarding the date and type of paint used during the most recent painting of the tower.

Because the fragile condition of the chips and their non-uniform surface contours made them unsuitable samples for spectrophotometry, the paint chips were visually evaluated by NBS personnel under a controlled visual environment and their color described using the Munsell renotation system. The color designations were made using $45^{\circ}$ illumination and perpendicular viewing. The source of illumination was a system using Macbeth Norlite D7500 fluorescent lamps. The Munsell renotation was then converted to CIE notation using the tables and charts in Wyszecki and Stiles [3].

Every chip obtained from each site was not evaluated. Chips were selected for evaluation which were noticeably different from others gathered at the same site. In some cases, only a small portion of a chip was evaluated.

Since the conversion charts are based on CIE Illuminant $C$, and the paint chips were initially described using a D7500 source, an adjustment factor was obtained to account for the differences in chromaticity due to the different sources.

In order to obtain an adjustment factor, ten colored samples were selected from Federal Standard 595 on the basis that their chromaticity coordinates were in the same general range as those of the chips from the tower sites. The spectral reflectance properties of each of these 10 samples was then obtained using a recording spectrophotometer automated with digital interface equipment. Chromaticity coordinates were then computed for both Source $C$ and D7500 illuminants. Source $C$ has a correlated color temperature of $6770 \mathrm{~K}$ and is representative of the spectral energy distribution of overcast skylight. A comparison of the results for the two sources provided adjustment factors which were then applied to convert the $\mathrm{D} 7500$ results to Source C results.

The adjusted chromaticities (Source C) are listed in Tables 1 and 3. Also tabulated in Table 3 are the averages of the individual numerical ratings of the appearance (color) of the 
towers visited during the initial ground observations, obtained as a result of the subjective evaluations.

The chromaticity coordinates listed in Tables 1 and 3 are plotted in figure 1, a portion of a CIE chromaticity diagram. Also shown are the boundary limits for ICAO orange and FAA aviation surface orange. The so-called boundary limits for FAA aviation orange were obtained by joining with straight lines the coordinate points of the hue and chroma (saturation) limit colors on the color tolerance chart. It is interesting to note that the H-(red limit) point plots outside of the ICAO limits.

The possibility exists that the orange paint at the base of a tower, from which paint chips were obtained, was not representative of the upper portions of the tower. However, results obtained through colorimetry of the paint chips correlated well with the ground and in-flight field observations. It was considered not feasible to attempt obtaining paint chips from higher portions of the tower.

\section{DISCUSSION OF PREVIOUS EXPERIMENTS}

Middleton's work on the conspicuity of orange surface colors [4] is pertinent to the present problem. Middleton used six individual targets, six foot square, at distances from $41 / 4 \mathrm{miles}$ to $61 / 4 \mathrm{miles}$. The panels faced south and were therefore illuminated by the sun when it was not obscured by clouds. Observations took place in all seasons and the visual backgrounds included snow, vegetation which varied seasonally, light brown grass, fresh green grass, and the forest. The observers indicated the order of conspicuity of the six panels as a chromatic signal. A description of the six colors used by Middleton is given in Table 4 .

One of the colors, No. 3, corresponds very closely to FAA aviation orange. The first five colors formed a series ranging from bright yellow to a deep reddish orange; the sixth was designed to be similar in hue to aviation orange but of lower saturation, to correspond to a weathered surface of that paint.

The results showed that color No. 1, a bright yellow, is totally unsatisfactory as a chromatic signal, despite being very conspicuous against dark backgrounds. When seen from a distance, this color frequently resembled that of a patch of sand or light soil.

Against the forest background the order of conspicuity of colors 2 to 5 was the order of their reflectances. The performance of No. 6, designed to simulate weathered or slightly soiled aviation orange, was the poorest.

Against the snow background, aviation orange, No. 3, was the superior color. Color No. 6 again made the poorest showing. 


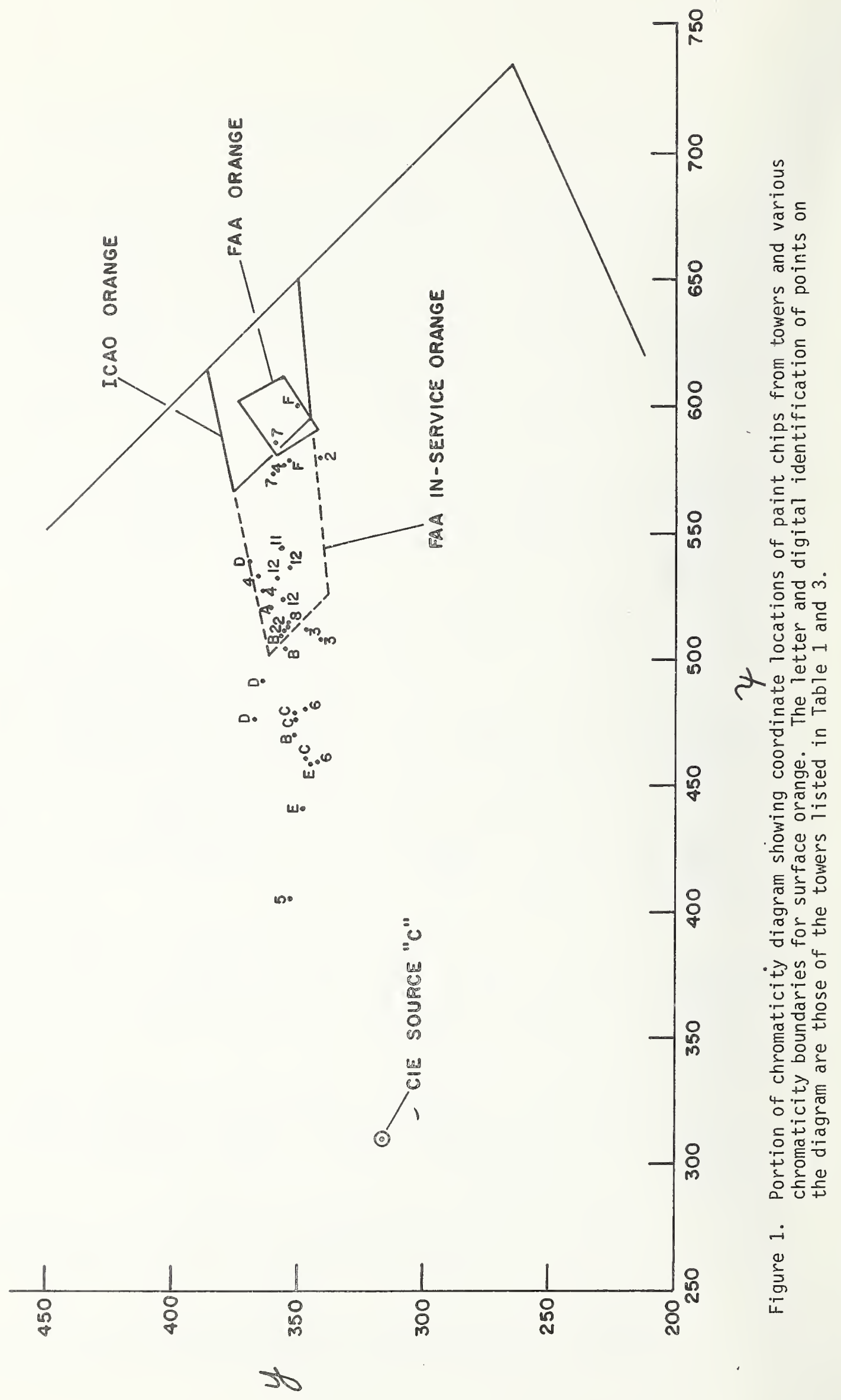


TABLE 4

Description of Six Colors Used by Middleton

\begin{tabular}{|c|c|c|c|c|c|c|}
\hline \multirow[b]{2}{*}{ No. } & \multirow[b]{2}{*}{ Composition } & \multirow{2}{*}{$\begin{array}{c}\text { Reflectance } \\
Y\end{array}$} & \multicolumn{2}{|c|}{$\begin{array}{l}\text { Chromaticity } \\
\text { Coordinates }\end{array}$} & \multicolumn{2}{|c|}{$\begin{array}{l}\text { Munsell } \\
\text { Renotation }\end{array}$} \\
\hline & & & $x$ & y & $\mathrm{H}$ & $\mathrm{V} / \mathrm{C}$ \\
\hline 1 & $\begin{array}{l}\text { Medium Chrome } \\
\text { Yellow }\end{array}$ & 0.512 & 0.501 & 0.471 & $1.5 Y$ & $7.5 / 15.2$ \\
\hline 2 & $\begin{array}{l}\text { Aviation Orange } \\
\text { and Med. Chrome } \\
\text { Yellow }\end{array}$ & .226 & .573 & .407 & $3 Y R$ & $5.3 / 15.0$ \\
\hline 3 & Aviation Orange & .142 & .608 & .363 & $0.5 Y R$ & $4.3 / 14$ \\
\hline 4 & $\begin{array}{l}\text { Aviation Orange } \\
\text { and Toluidine } \\
\text { Red }\end{array}$ & .114 & .620 & .339 & $9 \mathrm{R}$ & $3.9 / 16$ \\
\hline 5 & $\begin{array}{l}\text { Aviation Orange } \\
\text { and Toluidine } \\
\text { Red }\end{array}$ & .086 & .654 & .321 & $8 R$ & $3.4 / 16$ \\
\hline 6 & $\begin{array}{l}\text { Aviation Orange } \\
\text { and Light Chrome } \\
\text { Red }\end{array}$ & .121 & .588 & .373 & IYR & $4.0 / 12.4$ \\
\hline
\end{tabular}


Color No. 3 maintained a slight superiority against the grass background.

Middleton concluded that aviation orange, No. 3, was the most conspicuous color among those chosen when the whole range of natural backgrounds was taken into account, although a lighter and yellower color was more conspicuous against a forest background. Middleton had predicted this earlier on a theoretical basis [5].

His second conclusion was that it is essential to keep this color clean and fresh, or in other words to maintain a high chroma. Color No. 6, which gave poor results throughout, could easily pass for a moderately weathered specimen of aviation orange. Middleton considered his paper as documenting the necessity for maintaining these orange paints in very good condition.

It should be noted that Middleton's conclusion, regarding the use of yellow against a forest background, was based on the use of a single conspicuous color as a signal. It is precisely for the reason that obstructions are viewed against a variety of backgrounds that the FAA-prescribed marking pattern consists of alternating orange and white. The white is conspicuous in situations where the orange is deficient, i.e., against a dark forest background.

In a separate but related study, Judd and Yonemura [6] concluded that international orange is more conspicuous than black against a dark-foliage surround; and black is more conspicuous than international orange for a light-foliage surround. For average foliage international orange is more conspicuous at large angular subtense (greater than 10 minutes of arc); and black is more conspicuous at small subtense. The virtue of international orange is that it is fairly conspicuous against all foliage backgrounds.

\section{RECOMMENDATIONS AND DISCUSSION}

It is recommended that the FAA adopt limit boundaries to determine the acceptability of the color of in-service orange painted obstructions. The acceptable area of chromaticities is bounded by the spectrum locus and the following boundaries as plotted on the 1931 CIE chromaticity diagram:

$$
\begin{aligned}
& y=0.100 x+0.285 \text { (red boundary) } \\
& y=0.862-x \text { (white boundary) } \\
& y=0.220 x+0.250 \text { (yellow boundary) }
\end{aligned}
$$


The coordinates of the points of intersection of the white boundary with the red and yellow boundaries are $x=0.525, y=$ 0.337 and $x=0.502, y=0.360$. These "in-service" boundaries are plotted on figure 1 . The solid lines are the existing boundaries for ICAO orange. The dashed lines represent the additional limits recommended in this report. The red and yellow in-service boundaries recommended for faded orange are extentions of the existing red and yellow limits of ICAO orange. These boundaries approximate the constant hue lines between ICAO orange and CIE Source $C$.

Associated with the expanded limits on chromaticity are upper and lower limits on the reflectance of the orange paint. The maximum reflectance permitted is $Y_{\max }=0.21$. The minimum reflectance allowed varies according to the location of the sample within the orange boundaries. This limitation is represented by the equation

$$
Y_{\text {min }}=0.452-0.541 x
$$

which requires minimum reflectances which vary from 0.18 for the minimum saturation permitted to 0.10 for saturated colors at the spectrum locus.

The area delineated by the dashed lines, used in conjunction with the limitations on reflectance, includes the chromaticities of the paint chips from those towers regarded as acceptable or not deteriorated enough to be regarded as unacceptable. Requiring the reflectance $Y_{m i n}$ to be a function of the chromaticity coordinate $x$ permits the continued in-service use of those few relatively desaturated orange surfaces whose reflectance was such that their appearance was not unacceptable.

At first glance, the recommended boundaries for in-service orange may seem to allow colors which are too desaturated. However, these boundaries are consistent with the visual data obtained -- to use more restricted boundaries would be tantamount to ignoring the results of the observations.

As noted earlier, it is unimportant for an aviator to identify the orange color as such. This checks well with the observations where it seems that the chromaticness of the orange per se is not important in establishing the acceptability of a tower's appearance. In this regard, the conclusions stated in this report differ from those of Middleton described earlier. As discussed in section 6, Middleton's conclusion was based on the use of a single conspicuous color as a signal. 
In order to facilitate the field evaluation of in-service orange paint, it is recommended that a pair of color tolerance charts, designated as $\mathbf{Y}_{\max }$ and $Y_{\min }$ be developed, similar to the presently available "Aviation Surface Orange Color Tolerance Chart" used for new paint. Each chart would display non-glossy color chips (squares) with chromaticity coordinates at the eight locations indicated on figure 2. Each of the eight chips on the chart would have a reflectance of 0.21 corresponding to the maximum allowable reflectance. The eight chips on the $Y_{m i n}$ chart have reflectances as a function of their position computed using equation 4. The chromaticity coordinates, and equivalent Munsell notation, of the eight $Y_{\max }$ chips and the eight $Y_{\min }$ chips are listed in Table 5 .

The spacing of the color chips along the red and yellow boundaries was obtained through the use of a 1960 CIE uniformchromaticity-scale diagram (UCS). After the red and yellow boundaries were plotted on the UCS diagram, points were located that divided these boundaries into four equal portions between the white boundary and the spectrum locus. These points were then transformed back into the 1931 CIE system and, together with the two intersection points on the white boundary, provide the locations of the eight proposed color chips, as shown in figure 2 .

When using the new charts to evaluate in-service orange painted surfaces, an acceptable orange surface would be one redder than the colors lying along the yellow boundaries, yellower than the colors lying along the red boundaries, more saturated than the colors forming the white boundaries, no lighter than its nearest color match on the $Y_{\max }$ card, and no darker than its nearest color match on the $Y_{\text {min }}$ card. 


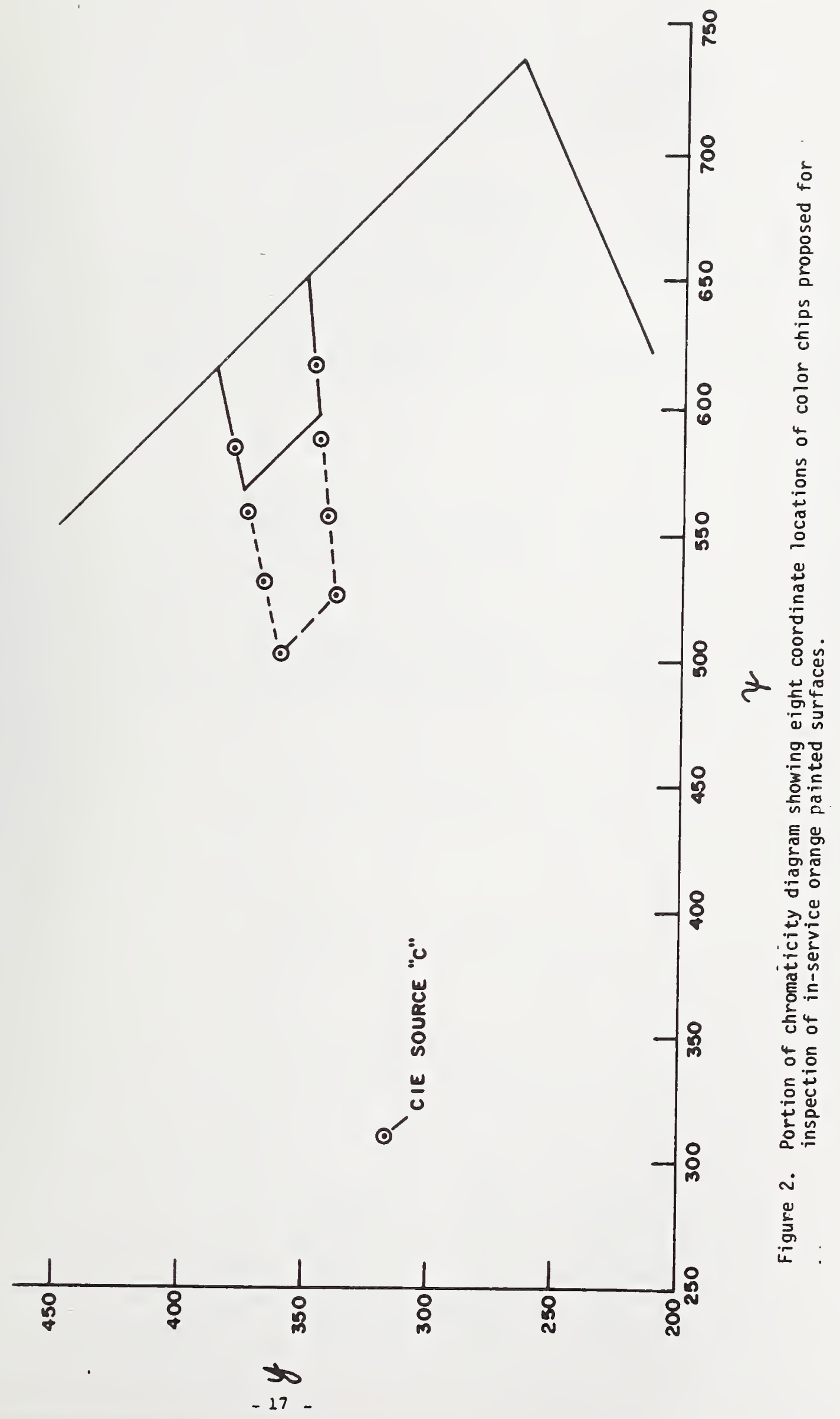




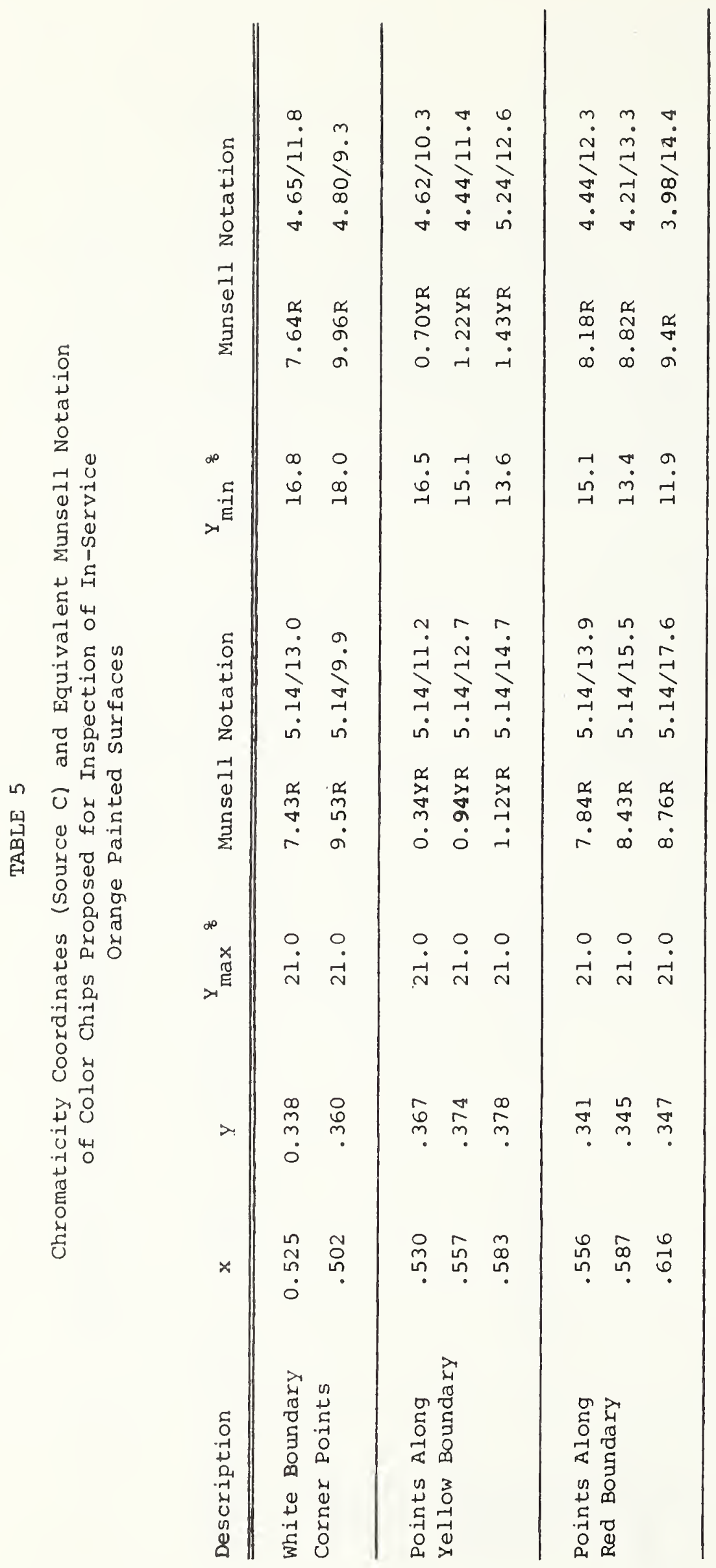




\section{REFERENCES}

1. Booker, R. L., Interim Report on the Marking of obstructions, NBS Report of Test, March 18, 1974.

2. Middleton, W.E.K., Vision Through the Atmosphere, Univ. of Toronto Press, 1952.

3. Wyszecki, G. and Stiles, w. S., Color Science, Wiley, New York 1967.

4. Middleton, W.E.K., A Study of the Conspicuity of Orange Surface Colors, Illuminating Engineering, 95, 1952.

5. Middleton, W.E.K., The Colors of Distant Objects, JOSA 40,373 , 1950.

6. Judd, D. B. and Yonemura, G. T., Target Conspicuity and Its Dependence on Color and Angular Subtense for Gray and Foliage Green Surrounds, NBS Report 10-120, November 1969. 
List of Individuals Comprising Group

Which Visited Tower Sites in Washington, D. C. Area on November 19, 1973

Name
Walter Fisher
Stanley Kingham
Joseph Scarlata
Gerald Gibson
Addison Fowler
Joseph Thomas
Carlos Roberts
Charles Douglas
Robert Booker
Gerald Howett

$\underline{\text { Name }}$

Walter Fisher

Stanley Kingham

Organization

FAA-ARD- 320

FAA-AAT- 242

FAA-AAT-242

FAA-AFS -460

FAA-AAS-550

Federal Communications Commission

Federal Communications Commission

National Bureau of Standards

National Bureau of Standards

National Bureau of Standards 
NBS.114A IREV. T-73)

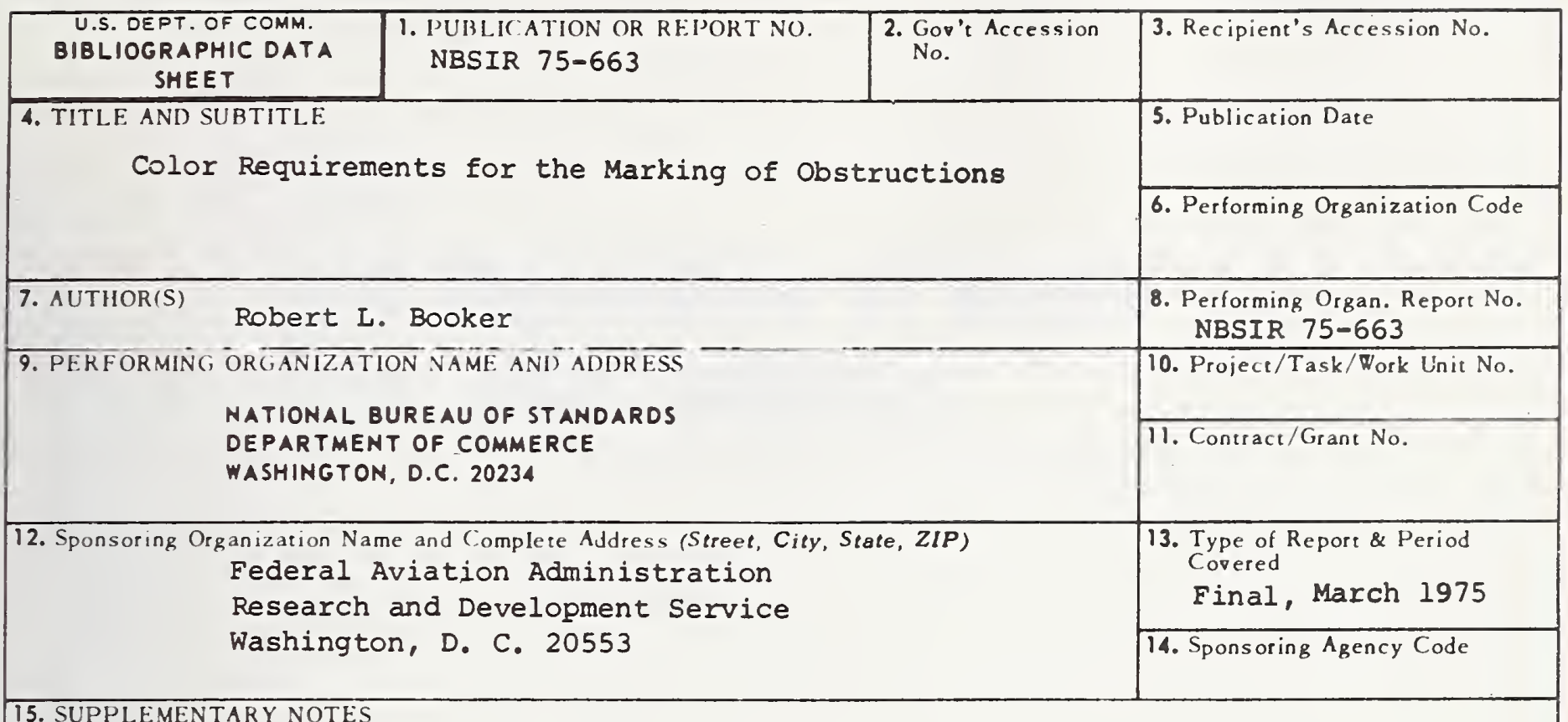

16. ABSTRACT (A 200-word or less factual summary of most significant information. If document includes a significant bibliography or literature survey, mention it here.)

Present methods and problems associated with the surface marking of obstructions to aviation, such as tall towers, are discussed. The correlation of subjective evaluations of appearance, from both ground and air observations, with the physical characteristics of the orange-painted sections of selected towers is described. Recommendations regarding the in-service appearance of orange paint consist of expanded chromaticity limits in combination with specific restrictions on reflectance. A suggested method of field implementation consists of using color tolerance charts displaying colored squares which depict the limit of the chromaticity and reflectance requirements.

17. KEY WORDS (six to twelve entries; alphabetical order, capitalize only the first letter of the first key word unless a proper name; separated by semicolons)

Aviation orange paint; color marking of obstructions; obstruction marking; visibility of towers.

18. AVAILABILITY [] Unlimited

x For Official Distribution. Do Not Release to NTIS

[] Order From Sup. of Doc., U.S. Government Printing Office Washington, D.C. 20402 , Si) Cat. No. C.13

[ Order From National Technical Information Servicc (NTIS) Springfield, Virginia 22151

\begin{tabular}{|l|c|}
\hline $\begin{array}{l}\text { 19. SECURITY CLASS } \\
\text { (THIS REPURT) }\end{array}$ & 26 \\
UNCL ASSIFIED & 26. OF PAGES \\
\hline $\begin{array}{l}\text { 20. SECURITY CLASS } \\
\text { (THIS PAGE) } \\
\text { UNCLASSIFIED }\end{array}$ & Price \\
\hline
\end{tabular}


